\title{
The functional domains of the Drosophila morphogen dorsal: evidence from the analysis of mutants
}

\author{
Kazuyoshi Isoda, Siegfried Roth, ${ }^{1}$ and Christiane Nüsslein-Volhard \\ Max-Planck-Institut für Entwicklungsbiologie, D-7400 Tübingen, Germany
}

\begin{abstract}
The dorsal (dl) protein is a member of the Rel family of transcription factors. It is distributed in a nuclear concentration gradient along the dorsoventral axis of Drosophila embryos and activates or represses a discrete set of zygotic genes in a concentration-dependent manner. The nuclear uptake of the $d I$ protein is stimulated by products of the dorsal group genes but inhibited by the cactus (cact) product. To analyze the functional domains of the $d l$ protein, we sequenced $11 \mathrm{dl}$ alleles and studied their interaction with cact. Four of these alleles were found to result in carboxy-terminal truncations of the protein. A deletion of 80 carboxy-terminal amino acids abolishes the ability of $d l$ protein to activate the expression of mesodermal genes. Larger deletions also affect the repressor function of $d l$. However, a protein consisting only of the Rel homologous region still acts as a weak repressor of zerknüllt transcription. A missense mutation in the presumptive DNA-binding domain causes a complete lack-of-function phenotype in trans to a deficiency but exerts a dominant-negative effect in trans to a wild-type copy of $d l$. These and genetic data with the alleles that produce truncated proteins indicate that $d l$ oligomerizes. The proteins truncated at the carboxy-terminal end show increased levels of nuclear uptake dorsally, but they still respond to the cact-mediated inhibition of nuclear transport. Therefore, carboxy-terminal sequences influence the cytoplasmic retention, although a domain of $d$ l-cact interaction resides in the amino-terminal portion.
\end{abstract}

[Key Words: cactus; dorsoventral polarity; NF-кB; nuclear localization; rel; transcription factor]

Received November 28, 1991; revised version accepted January 23, 1992.

The dorsal $(d l)$ protein is a morphogen that forms a nuclear concentration gradient along the dorsoventral axis of Drosophila embryos (Roth et al. 1989; Rushlow et al. 1989; Steward 1989|. It belongs to the Rel family of transcriptional regulators (Steward 1987), which includes the protein encoded by the c-rel proto-oncogene, among others (Stephens et al. 1983; Wilhelmsen et al. 1984; Bull et al. 1990; Capobianco et al. 1990), and the p50 and p65 subunits of NF-кB (Baeuerle and Baltimore 1988; Ghosh et al. 1990; Kieran et al. 1990; Nolan et al. 1991; Ruben et al. 1991). A region of $\sim 300$ amino acid residues in the amino-terminal half, the Rel homology $(\mathrm{RH})$ domain, is conserved in the various Rel family proteins.

The DNA-binding region of Rel family proteins resides in the RH domain (Gilmore 1991). DNA-binding sites have been characterized for NF-kB (Baeuerle 1991). They reveal an imperfect palindrome, the $\kappa B$ motif, as a consensus binding sequence for NF- $\mathrm{BB}$. Homo- or heterodimerization has been found for most Rel-related proteins and seems to be a necessary prerequisite for their function as transcriptional regulators (Kieran et al. 1990;

${ }^{1}$ Present address: Department of Molecular Biology, Princeton University, Princeton, New Jersey 08544 USA. lnoue et al. 1991; Logeat et al. 1991; Nolan et al. 1991; Urban et al. 1991).

dl protein also binds DNA via its RH domain (Ip et al. 1991). The identified binding sites in the zerknüllt (zen) and $t$ wist ( $t w i$ ) promoters resemble those of NF- $\mathrm{kB}$ (Ip et al. 1991; Jiang et al. 1991; Pan et al. 1991; Thisse et al. 1991). However, although NF- $\mathrm{BB}$ binding so far has been found to lead only to the activation of target genes, the $d l$ protein is thought to act as an activator of some and a repressor of other genes in the same nucleus. In the ventral-most region of the embryo where the $d l$ protein reaches its highest nuclear concentrations, it stimulates the expression of $t w i$ and snail (sna), two genes required for mesoderm formation, and represses the expression of zen and decapentaplegic (dpp), both involved in the specification of dorsally derived structures (Irish and Gelbart 1987; Rushlow et al. 1987; Roth et al. 1989; Ray et al. 1991).

The activity of the Rel-related proteins is not regulated primarily at the level of transcription or translation but, rather, depends on the controlled nuclear uptake of protein constitutively present in the cytoplasm (Baeuerle 1991). Cytoplasmic NF-kB and c-Rel are complexed with I B and pp40, respectively, which function as inhibitors of nuclear transport and DNA binding. I $\mathrm{B}$ and $\mathrm{pp} 40$ 
probably block the usage of the nuclear localization signal (NLS) found at identical positions in all known Relrelated proteins (Baeuerle and Baltimore 1988; Davis et al. 1991; Haskill et al. 1991; Kerr et al. 1991; Nolan et al. 1991). The NF- $\mathrm{B} / \mathrm{I} \kappa \mathrm{B}$ complex dissociates (or undergoes a structural change), presumably upon phosphorylation of $I \kappa B$, so that nuclear transport and DNA binding can occur (Ghosh and Baltimore 1990). Thus, the activity of the Rel family proteins appears to be linked to extracellular signals via the modification of inhibitor proteins.

The formation of the nuclear $d l$ protein gradient also occurs by regulation of nuclear uptake (Roth et al. 1989; Rushlow et al. 1989; Steward 1989). The $d l$ protein is first distributed uniformly in the embryonic cytoplasm. During the syncytial blastoderm stage, the ventral nuclei accumulate the highest $d l$ protein amounts, lateral nuclei gain intermediate levels, and no (detectable) uptake of the $d l$ protein into dorsal nuclei occurs. Because the nuclear dl protein activates and represses zygotic dorsoventral genes in a concentration-dependent fashion, the shape of the nuclear $d l$ protein gradient determines the spatial pattern of cell differentiation along the dorsoventral axis. Eleven factors are known to be required for the regulation of the nuclear uptake of the $d l$ protein. Ten of these constitute (together with $d l$ ) the dorsal group (Anderson and Nüsslein-Volhard 1986), whose products act to promote nuclear localization ventrally. Only one component, encoded by the gene cactus (cact), so far is known to act as an inhibitor of nuclear localization (Roth et al. 1991).

The dorsal group genes control a complicated sequence of events, which includes the formation of an extracellular signal and its transmission to the cytoplasm by a transmembrane receptor, the product of the Toll gene (Hashimoto et al. 1988; Stein et al. 1991). Only two of the dorsal group genes, pelle $(p l l)$ and tube $(t u b)$, function like $d l$ inside the embryo (Letsou et al. 1991; K.V. Anderson, pers. comm.), suggesting that they are more directly involved in the nuclear uptake of the $d l$ protein. The products of $p l l$ and tub must counteract the inhibition of nuclear transport exerted by cact.

To define functional domains of the $d l$ protein, we have sequenced $11 \mathrm{dl}$ alleles and studied their phenotypes alone and in double mutants with cact. The correlation of sequence alterations with phenotypic features of these $d l$ alleles is consistent with the idea that $d l$, like the other Rel family proteins, has an amino-terminal DNA-binding domain and a carboxy-terminal domain required for transcriptional activation/repression. The phenotypes resulting from truncated proteins indicate that both amino- and carboxy-terminal regions of $d l$ protein are involved in the regulation of nuclear transport. Furthermore, we describe dominant effects that indicate a self-association of the $d l$ protein.

\section{Results}

Of 17 ethylmethane sulfonate (EMS)-induced $d 1$ alleles, 6 are complete loss-of-function (amorphic) alleles, as judged by genetic criteria. No protein was detected in embryonic extracts of these six alleles, indicating that their mutant phenotype is caused by a defect in transcription or translation (Roth et al. 1989). To gain information on the functional organization of the $d l$ protein, we sequenced the coding region of the remaining 11 alleles. Each of these 11 alleles exhibits some residual gene function, in one case detectable only as a dominant-negative (antimorphic) effect $\left(d l^{D 7}\right)$. The $d l$ protein distribution and the Western blot analysis of most of these alleles have been described earlier (Roth et al. 1989) and are summarized in Table 1.

\section{Phenotypic classification of $\mathrm{dl}$ alleles}

The $d l$ alleles can be grouped according to the strength of the mutant phenotype (Nüsslein-Volhard 1979; Anderson et al. 1985; Anderson and Nüsslein-Volhard 1986). Weak alleles $\left(d l^{S C}\right.$ and $d l^{S G}$ at $22^{\circ} \mathrm{C} ; d l^{P Z}$ and $d l^{2}$ at $\left.18^{\circ} \mathrm{C}\right)$ cause a deletion of mesoderm but allow the formation of some ventral and lateral epidermis (weak dorsalization, D2). The weak dorsalization is characterized by the absence of twi expression ventrally (Roth et al. 1989). Because twi transcription is activated by the $d l$ protein (Jiang et al. 1991; Pan et al. 1991; Thisse et al. 1991), the weakly dorsalizing alleles are defective in transcriptional activation. On the other hand, the determination of ventral and lateral epidermis found in D2 embryos occurs via the repression of genes like zen and $d p p$ (Irish and Gelbart 1987; Ip et al. 1991; Ray et al. 1991). The zen expression domain is only slightly expanded in D2 embryos as compared with wild type (Roth et al. 1989). Hence, weakly dorsalizing $d l$ alleles have normal or only slightly impaired repressor functions.

In addition to a loss of mesoderm, stronger $d l$ alleles $\left\{d l^{(2 F}, d l^{5}, d l^{P^{\prime} Z}\right.$, and $d l^{2}$ at $\left.22^{\circ} \mathrm{C}, d l^{O 11}, d l^{I 5}, d l^{Q D}, d l^{3}\right)$ also lead to a loss of ventral epidermis /strong dorsalization, D1). The cuticle of strongly dorsalized embryos consists only of lateral and dorsal pattern elements. The zen expression domain of $\mathrm{Dl}$ embryos is strongly expanded toward the ventral side of the embryo (Roth et al. 1989|. These alleles therefore code for $d l$ proteins that not only have lost their activating function but are, in addition, only weak transcriptional repressors.

Finally, completely dorsalizing alleles $\left(d l^{D 7} / D f\right)$ lead to apolar embryos that differentiate only dorsal epidermis (complete dorsalization, D0). Neither activation of $t w i$ nor repression of zen or $d p p$ occurs. zen and $d p p$ are expressed uniformly around the entire embryonic circumference (Rushlow et al. 1987; Ray et al. 1991). dl mutations causing such phenotypes have lost their function as transcriptional regulators entirely.

\section{Amino acid changes of $11 \mathrm{dl}$ alleles}

The results of our sequence analysis are shown in Figure la and Table 1. A single amino acid change was detected in each of the 11 alleles. Eight alleles, $d l^{D 7}, d l^{2}, d l^{3}, d l^{S C}$, $d l^{5}, d l^{U 5}, d l^{Q D}$, and $d l^{S G}$, show normal amounts of protein in whole embryos or in embryonic extracts (Table 1; Roth et al. 1989; Roth 1990). Therefore, it seems that the 
Table 1. Amino acid changes found in $11 \mathrm{dl}$ alleles

\begin{tabular}{|c|c|c|c|c|}
\hline Allele & Amino acid change & Phenotype & $\begin{array}{l}d l \text { protein in } \\
\text { whole embryos }\end{array}$ & $\begin{array}{l}d l \text { protein in } \\
\text { embryonic extracts }^{a}\end{array}$ \\
\hline \multicolumn{5}{|c|}{ Amino-terminal group } \\
\hline D7 & Arg-63 $\rightarrow$ Cys & Do & normal & normal abundance $(85 \mathrm{kD})$ \\
\hline 2 & Gly- $68 \rightarrow$ Glu & $\mathrm{D} 1\left(22^{\circ} \mathrm{C}\right) \mathrm{D} 2\left(18^{\circ} \mathrm{C}\right)^{\mathrm{b}}$ & normal & normal abundance (85 kD) \\
\hline$Q F$ & Ser-103 $\rightarrow$ Phe & Dl & reduced abundance & absent \\
\hline$S C$ & Cys- $124 \rightarrow$ Ser & D2 & normal & normal abundance $(85 \mathrm{kD})$ \\
\hline 5 & Val-188 $\rightarrow$ Met & D1 & normal & normal abundance $(85 \mathrm{kD})$ \\
\hline$P Z$ & Arg- $310 \rightarrow$ His & $\mathrm{D} 1\left(22^{\circ} \mathrm{C}\right) \mathrm{D} 2\left(18^{\circ} \mathrm{C}\right)^{\mathrm{C}}$ & absent & absent \\
\hline \multicolumn{5}{|c|}{ Carboxy-terminal group } \\
\hline 011 & Gln-339 $\rightarrow$ stop & $\mathrm{D} 0 / \mathrm{Dl}^{\mathrm{d}}$ & absent & absent \\
\hline U5 & Gln- $488 \rightarrow$ stop & Dl & nuclear gradient extended ${ }^{\mathrm{e}}$ & normal abundance $(45,52,60 \mathrm{kD})$ \\
\hline$Q D$ & Trp-524 $\rightarrow$ stop & D1 & nuclear gradient extended ${ }^{\mathrm{c}}$ & normal abundance $(56,60,68 \mathrm{kD})$ \\
\hline 3 & Ala-53l $\rightarrow$ Val & D0-Dl & normal $^{\mathrm{f}}$ & reduced abundance $(85 \mathrm{kD})$ \\
\hline$S G$ & Gln-598 $\rightarrow$ stop & D2 & nuclear gradient extended ${ }^{\mathrm{c}}$ & normal abundance $(70 \mathrm{kD})$ \\
\hline
\end{tabular}

${ }^{\mathrm{a}}$ The data in these columns are cited from Roth et al. (1989) and Roth (1990).

${ }^{\text {b}}$ The phenotype of $d l^{2}$ is only weakly rescued at $18^{\circ} \mathrm{C}$. The mutant embryos show small amounts of ventral epidermis if they develop at $18^{\circ} \mathrm{C}$. The temperature-sensitive period comprises the syncytial blastoderm stage (Anderson and Nüsslein-Volhard 1986).

${ }^{c} d l^{1 P}$ allows the formation of normal amounts of ventral epidermis at $18^{\circ} \mathrm{C}$. In contrast to $d l^{2}$, the temperature-sensitive period of $d l^{P Z}$ is restricted to late stages of oogenesis (Anderson and Nüsslein-Volhard 1986).

${ }^{\mathrm{d}}$ Twenty percent of the embryos have Filzkörper. The majority differentiate only dorsal epidermis; however, their zen expression and gastrulation movements are polarized (Fig. 2).

'Extended refers to the $d l$ protein distribution shown in Fig. 5c. In contrast to the wild-type distribution, the nuclei of the dorsal half contain detectable amounts of $d l$ protein.

${ }^{\mathfrak{t}}$ In variance to previously published data (Roth et al. 1989).

mutant phenotypes of these eight alleles are caused by defects in the protein and not by a simple reduction of transcription or translation owing to a mutation in an untranslated region. The three alleles whose protein could not be detected in Western blots $\left|d l^{011}, d l^{Q F}, d l^{P Z}\right|$ show phenotypes in trans to deficiencies or interactions with cact (see below), which cannot be explained by a mere reduction in transcript amount or translation efficiency. Therefore, in the case of these three alleles, we believe that the amino acid changes detected in the coding region are the cause of the mutant phenotype. Six mutants $\left(d l^{D 7}, d l^{2}, d l^{Q F}, d l^{S C}, d l^{5}\right.$, and $\left.d l^{P Z}\right)$, have an amino acid alteration in the amino-terminal half, the $\mathrm{RH}$ domain. In this paper, these six mutants are designated the amino-terminal group. The other five mutants $\left\langle\mathrm{dl}^{011}\right.$, $d l^{U 5}, d l^{Q l}, d l^{S G}$, and $d l^{3}$ ) show changes in the carboxyterminal half and are called the carboxy-terminal group.

Amino-terminal group of $\mathrm{dl}$ alleles Among the aminoterminal group, the mutations of $d l^{D T}, d l^{2}, d l^{Q F}$, and $d l^{S C}$ are located in or close to a region that is more basic than the rest of the RH domain (with the exception of the NLS). This basic subregion (approximately residues 40 120 ) has an isoelectric point (pI) of 10.3 , whereas the rest of the RH domain without NLS has a pI of 6.2. Because all DNA-binding domains known so far show a high density of basic amino acids (Mitchell and Tjian 1989; Harrison 1991), this subregion might contain the DNA-binding domain of the $d l$ protein.

Of the four mutations in or close to the basic subre- gion, only $d l^{177}$ leads to completely dorsalized embryos in trans to a deficiency. Hence, the $d l^{D 7}$ protein is nonfunctional as a transcription factor, although its amount and distribution are indistinguishable from the wild-type protein (Roth et al. 1989). $\mathrm{dl}^{D 7}$ causes a dominant-negative (antimorphic) effect: When transheterozygous to a wild-type copy, $d l^{D 7}$ leads to weakly dorsalized embryos (D2). Therefore, although nonfunctional on its own, $d l^{D 7}$ is able to compete with or partially inactivate the wildtype copy of $d l$.

$d l^{S C}$ shows an alteration at the margin of the basic subregion and acts as a weak mutation. In contrast, $d l^{2}$ and $d l^{Q F}$ show changes in residues of the basic subregion close to that of $d l^{D 7}$. Both lead to strongly dorsalized phenotypes at $22^{\circ} \mathrm{C}$. The normalization of the $d l^{2}$ phenotype at $18^{\circ} \mathrm{C}$ (Anderson and Nüsslein-Volhard 1986) suggests that the mutation impairs protein structure as observed for many proteins with reduced thermostability (Goldenberg 1988). The $d l^{Q F}$ protein was weakly detectable in whole embryos but not detectable in embryonic extracts, suggesting that the mutation affects protein stability.

The other two amino-terminal group mutants, $d l^{5}$ and $d l^{P Z}$, are located in the consensus sequences of two putative phosphorylation sites. $d l^{5}$ changes a putative target sequence for the phosphorylation of Ser-187 by protein kinase C. $d l^{5}$ is strongly dorsalizing but produces normal amounts of normal sized protein (Roth et al. 1989). The mutant protein forms a nuclear concentration gradient indistinguishable from a wild-type gradient (Fig. 
a
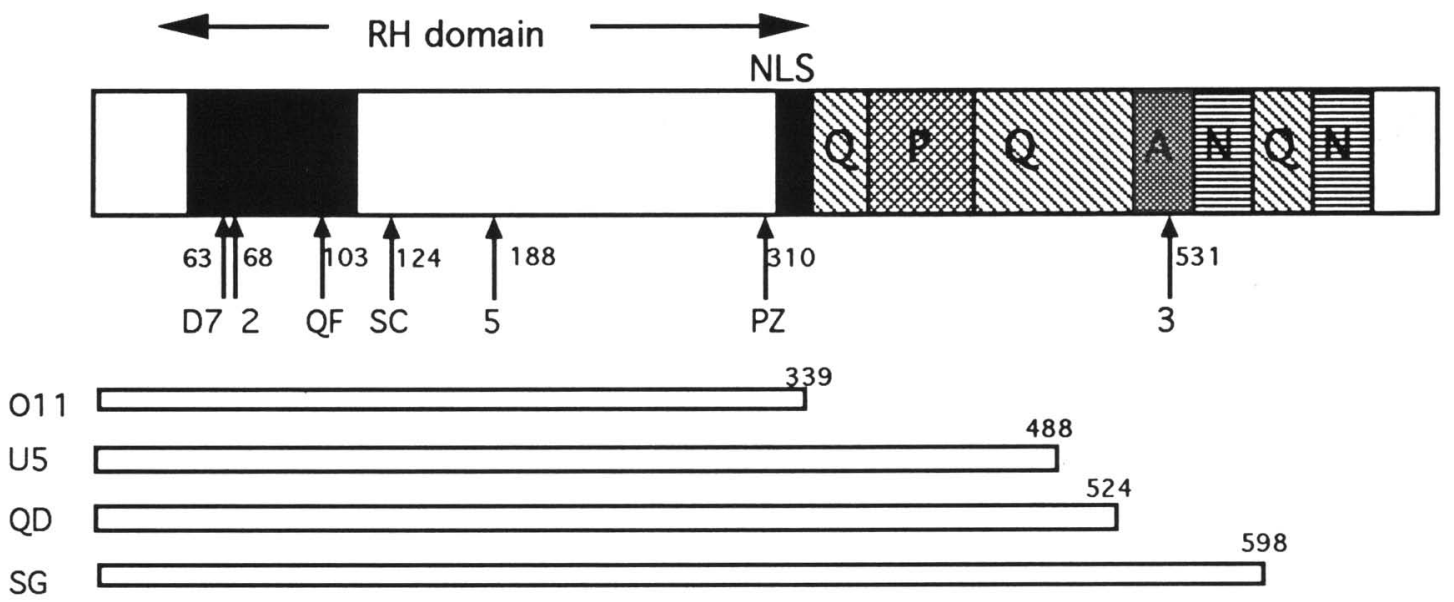

b

\begin{tabular}{|l|l|l|l|}
\hline $\begin{array}{l}\text { DNA } \\
\text { binding }\end{array}$ & Dimerization & Transcriptional activation/ repression \\
\hline
\end{tabular}

Figure 1. Mutations and proposed functional organization of the $d l$ protein. $\{a \mid$ A schematic drawing of the primary structure of the dl protein is shown. Solid areas indicate basic regions. (NLS) Nuclear localization sequence. Proline (P)-, glutamine (Q)-, asparagine $(\mathrm{N})$-, and alanine (A)-rich regions are patterned. Arrows indicate the positions of the mutations. The four open bars show the size of the four truncated proteins. (b) The model of the functional organization of the $d l$ protein combines data published earlier (Ip et al. 1991; Richardson and Gilmore 1991) with the analysis of the $d l$ alleles presented in this paper. (Cytoplasmic retention) Either a second cact-binding site or the site of interaction with a component not yet known.

5 a, below). The mutation in $d l^{1 / 2}$ changes the consensus sequence for the phosphorylation of Ser-312 by cAMP/ cGMP-dependent kinase. This sequence is conserved in all known Rel-related proteins. $d l^{\prime \prime} Z$ exhibits a strong temperature sensitivity (Anderson and Nüsslein-Volhard 1986) and shows impaired protein stability. The $d l^{P Z}$ protein is not detectable in embryonic extracts or whole embryos at $22^{\circ} \mathrm{C}$ (Table 1 ; Roth et al. 1989) in contrast to the proteins of all other hypomorphic alleles of comparable phenotypic strength. Like the $d l^{p Z}$ protein, many known temperature-sensitive proteins are also unstable (for review, see Goldenberg 1988).

Carboxy-terminal group of $\mathrm{dl}$ alleles Four of the carboxy-terminal group mutants are nonsense mutations, providing a series of deletions from the carboxy-terminal end (Fig. la). The shorter mutant proteins cause the more severe mutant phenotypes: Whereas $d l^{S G}$ (stop at amino acid 598) causes a weak dorsalization (D2), $d l^{Q D}$ (stop at amino acid 524) and $d 1^{U 5}$ (stop at amino acid 488) lead to strongly dorsalized embryos (D1, Fig. 3c, below). The strongest mutant phenotype is caused by $\mathrm{dl}^{011}$ (stop at amino acid 339), whose product consists only of the RH domain. The nonsense mutation of $d l^{O 11}$ is located in the region of the NLS. Only a small portion of the embryos $(20 \%)$ derived from $\mathrm{dl}^{011} / \mathrm{dl}^{-}$females differentiate lateral pattern elements visible in cuticle preparations (Fig. $3 \mathrm{e}$, below). However, ventral repression of zen and a weak polarization of the gastrulation movements were detectable in all mutant embryos (Fig. 2). This indicates that $d l^{011}$ has residual function as a transcription factor and is subject to some degree of spatial regulation.

The product of $d l^{O 11}$ was not detectable in embryonic extracts or whole embryos (Roth et al. 1989). Because the antibodies that we used were raised against a fusion protein containing only amino acids 145-570 of $d l$ (Roth et al. 1989), they may not detect the protein derived from $d l^{O 11} . d l^{U S}, d l^{Q D}$, and $d l^{S G}$ produce normal amounts of truncated protein but show alterations in the protein distribution. All three mutants cause an extension of the 


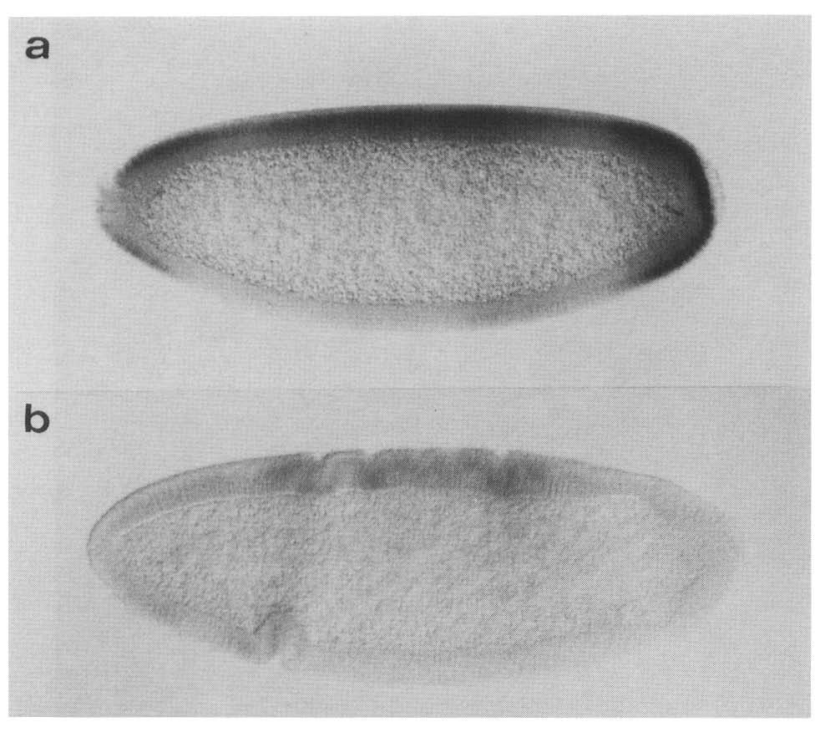

Figure 2. zen repression and gastrulation of $d l^{(011}$. Embryos derived from $d l^{011} / d l^{1}$ females were stained with anti-zen antibodies. Anterior is to the left; ventral is down. $(a)$ Blastoderm stage embryo. The zen expression is partially repressed at the ventral side. (b) Gastrulating embryo. The gastrulation movements are only weakly polarized. A germ band extension toward the dorsal side is often not visible (embryo shown here) or strongly reduced.

nuclear concentration gradient toward the dorsal side of the embryo (Table 1; Fig. 5c, below; Roth et al. 1989). As a result, the dorsally located nuclei, which exclude the wild-type protein, contain low levels of mutant protcin. This indicates that the carboxy-terminal region of the $d l$ protein influences the inhibition of nuclear transport.

The other carboxy-terminal group mutant, $d l^{3}$, is located in an alanine-rich region, which may form an $\alpha$-helix as predicted by the method of Garnier (1978). $d^{3}$ causes a strong dorsalization. In whole embryos, the $d l^{3}$ protein gradient appears normal; however, in embryonic extracts we detected only reduced amounts of protein.

\section{Interactions with cact}

On the basis of genetic experiments, a direct interaction of cact and $d 1$ products was proposed (Roth et al. 1991). Both cact and $d l$ are dosage sensitive. Females that have only one wild-type copy of $d l$ produce weakly dorsalized embryos at $29^{\circ} \mathrm{C}$ (Nüsslein-Volhard 1979). In contrast, females hemizygous for cact produce weakly ventralized embryos $150-90 \%$ of the embryos die with reduced dorsal anlagen; Roth et al. 1991). The cact haploinsufficiency is suppressed if the $d l$ dosage is reduced simultaneously with the cact dosage: Females lacking one copy of cact and one copy of $d l$ (cact ${ }^{-}+1+d^{-}$) have normal numbers of progeny at $22^{\circ} \mathrm{C}$. This suppression of the cact haploinsufficiency was observed with all amorphic, but only one group of hypomorphic, dl alleles (Table 2).
Amino-terminal group of $\mathrm{dl}$ alleles In transheterozygous combinations with cact, the hypomorphic $d l$ alleles of the amino-terminal group (except $d l^{D 7}$ ) behave like $d l$ deficiencies and amorphic $d l$ alleles. Females carrying these alleles in trans to a strong cact allele $\left(c a c t^{A 2}+/+\right.$ $d l^{*}$ ) have normal numbers or only slightly reduced numbers of progeny (Table 2; Fig. 3b). Thus, in this test the $d l$ alleles of the amino-terminal group behave like typical loss-of-function mutations resulting in a reduction of wild-type $d l$ activity. Because in the absence of cact function more wild-type $d l$ protein enters the nuclei at the dorsal side of the embryo (Roth et al. 1991), one would expect that homozygous double mutant combinations of the hypomorphic $d l$ alleles with cact similarly cause an increased import of the mutant protein at dorsal positions. Therefore, the embryos from the doubly mutant females (cact $\mathrm{dl}^{*} /$ cact $d \mathrm{l}^{*}$ ) should show a loss of dorsally derived structures and a compensating expansion of structures found only ventrally in the single mutant $\left(d l^{*} / d l^{*}\right)$. We observed this result with $d l^{2}, d l^{5}$, and $d l^{\text {SC }}$ (Table 3). The homozygous double mutants of cact and $d l^{2}, d l^{5}$, and $d l^{S C}$ cause a lateralized phenotype: Ventral or lateral pattern elements are present around the entire embryonic circumference; however, two of the amino-terminal group alleles, $d l^{Q F}$ and $d l^{P Z}$, behave differently. Instead of an expansion, they show a reduction of lateral and ventral pattern elements when cact is re-

Table 2. dl mutants transheterozygous to a strong cact mutation

\begin{tabular}{|c|c|c|}
\hline \multirow[b]{2}{*}{ dorsal allele } & \multicolumn{2}{|c|}{$\begin{array}{l}\text { Percent nonhatching larvae derived from } \\
\text { females of the genotype }\end{array}$} \\
\hline & $d l^{*} / \mathrm{CyO}$ & $+d l^{*} /$ cact $^{A 2}+($ phenotype $)$ \\
\hline \multicolumn{3}{|c|}{ Amorphic alleles } \\
\hline$D f(2 L) T W 119$ & 30 & 5 \\
\hline 1 & 10 & 10 \\
\hline 4 & NT & 3 \\
\hline 6 & NT & 10 \\
\hline 8 & NT & 5 \\
\hline 15 & NT & 15 \\
\hline \multicolumn{3}{|c|}{ Hypomorphic alleles: amino-terminal group } \\
\hline QF & NT & 5 \\
\hline$S C$ & NT & 20 \\
\hline 5 & NT & 30 \\
\hline 2 & NT & 15 \\
\hline$P Z$ & NT & $<1$ \\
\hline \multicolumn{3}{|c|}{ Hypomorphic alleles: carboxy-terminal group } \\
\hline 3 & 50 & $100(\mathrm{D} 2-\mathrm{D} 3)$ \\
\hline 011 & 55 & 100 (Ll polar) \\
\hline$Q D$ & 20 & 100 (L1 polar) \\
\hline U5 & 10 & 100 (Ll polar) \\
\hline$S G$ & 5 & 98 (Ll polar) \\
\hline
\end{tabular}

Eggs $(300-500)$ were scored at room temperature to determine the number of nonhatching larvae. D2 embryos have lost the mesoderm completely; D3 embryos have a reduced mesoderm. L1 refers to lateralized embryos that have deleted both ventral and dorsal anlagen. (NT) Not tested. 


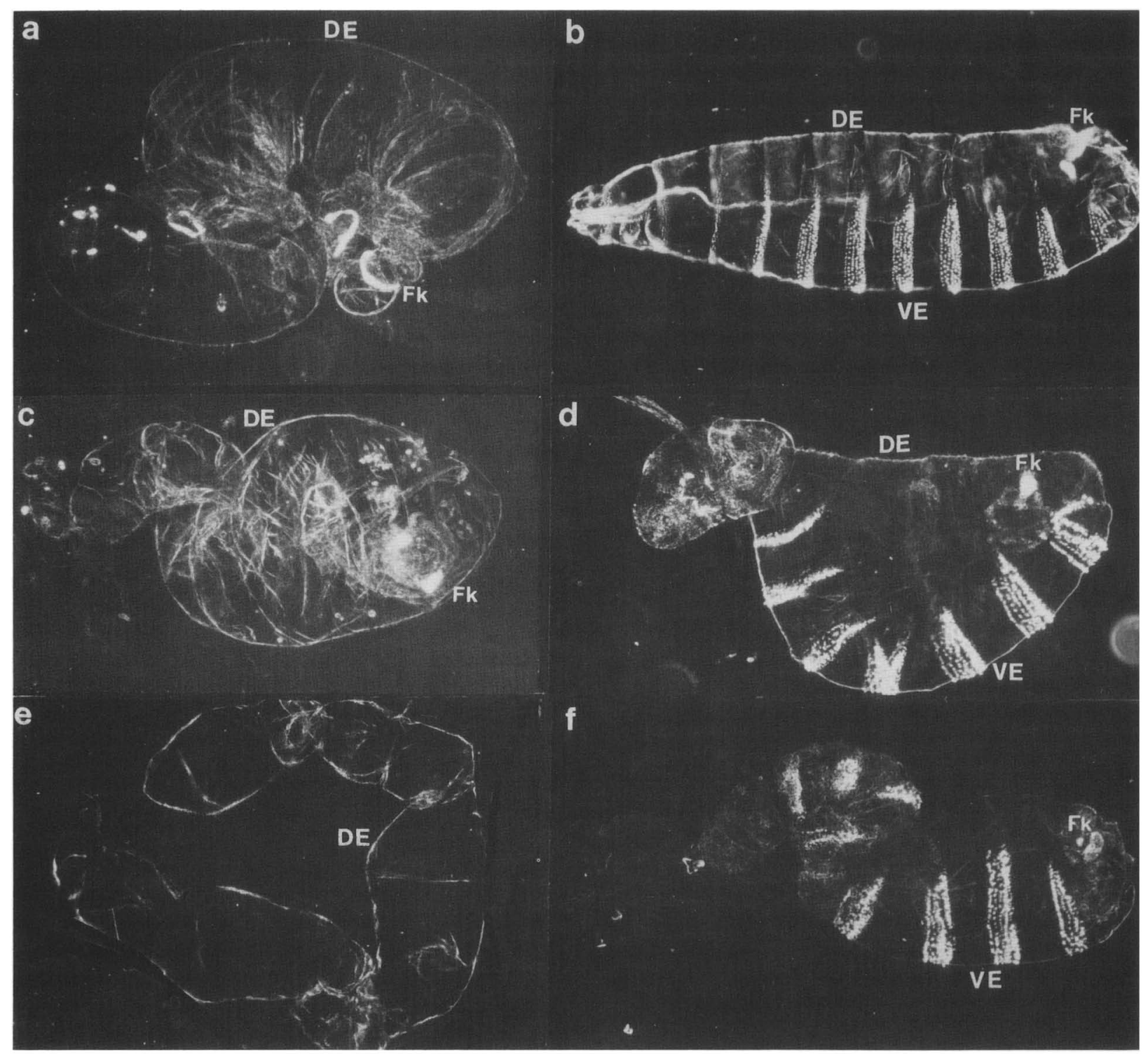

Figure 3. The cuticle pattern of $d l$ mutants transheterozygous for a strong cact mutation. Maternal genotypes: $(a) d l^{5} / D f(2 L) T W 119$. $(b)+d l^{5} / \mathrm{cact}^{A 2}+.(c) d l^{(Q I)} / D f(2 L) T W 119 .(d)+d l^{(2)} / \mathrm{cact}^{A 2}+.(e) d l^{(011} / D f(2 L) T W 119 .(f)+d l^{(11} / \mathrm{cact}^{A 2}+$. (Fk) Filzkörper; (DE) dorsal epidermis; (VE) ventral epidermis. Dorsal is up; anterior is to the left. The lack of ventral epidermis in $a$ and $c$ is characteristic of strongly dorsalized phenotypes (D1). In addition, the embryo in $e$ has lost the Fk, indicating that it is almost completely dorsalized. In transheterozygous combinations with cact, $d l^{5}$ leads to wild-type embryos and to a small portion $(30 \%)$ of embryos with slight head or telson defects $(b)$. In contrast, transheterozygous combinations with cact and $d l^{(D)}(d)$ or $d l^{(11}(f)$ cause an expansion of ventral epidermis at the expense of dorsal and dorsolateral structures in all mutant embryos. This fate map alteration leads to strong defects in the head, thorax, and telson region. Fk are absent or reduced in size and pulled inside the embryo.

moved. This is most striking with $d l^{12}$. Whereas $d l^{12 Z}$ $d l^{P Z}$ leads to embryos that possess nearly all elements of the wild-type pattern (D2) at $18^{\circ} \mathrm{C}$, $\operatorname{cact}^{A 2} d l^{P Z}$ / cact $^{A 2} \mathrm{dl}^{P Z}$ causes a complete dorsalization at $18^{\circ} \mathrm{C}$. Thus, $d l^{P Z}$ (and $d l^{Q F}$ ) show a positive requirement for cact activity. Their residual function is stabilized in the presence of cact but lost when cact is absent. Given the observation that the mutant proteins of both alleles could not be detected in embryonic extracts (Table 1), we propose that $d l^{Q F}$ and $d l^{P Z}$ form unstable proteins that acquire increased stability in complexes with the cact protein.

Carboxy-terminal group of $\mathrm{dl}$ alleles In contrast to the $d l$ alleles of the amino-terminal group, the hypomorphic $d l$ alleles of the carboxy-terminal group become completely (or almost completely) dominant if cact activity is reduced. Of the embryos derived from transheterozygous females $\left(\right.$ cact $\left.^{\mathrm{A2}}+1+\mathrm{dl}^{*}\right), 100 \%$ (or nearly $100 \%$ ) die (Table 2). The missense mutation, $d l^{3}$, causes a weak 
Table 3. Homozygous double mutant combinations of cact and the amino-terminal group of hypomorphic $\mathrm{dl}$ alleles

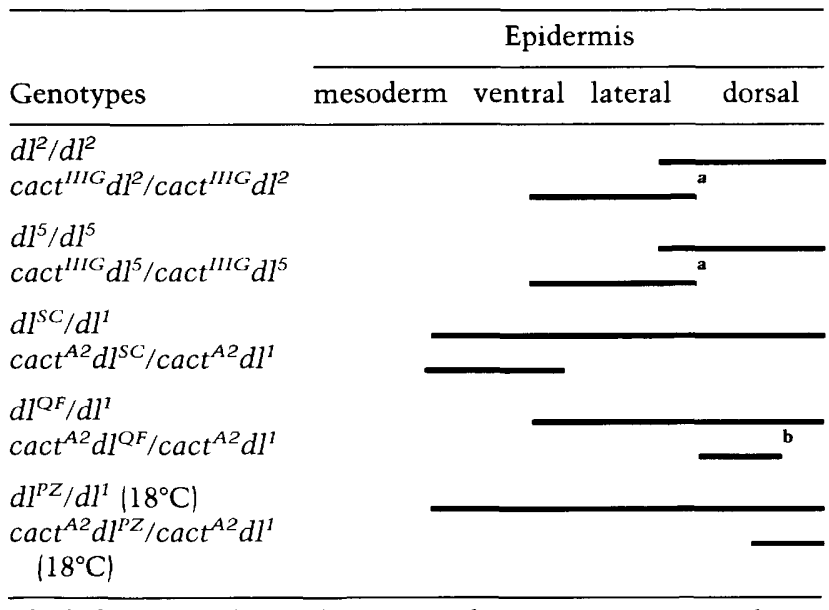

The bold rules indicate the pattern elements present in embryos derived from mutant females.

${ }^{a}$ The ventral denticles present in these embryos are very faint and probably derived from the dorsal margin of the ventral epidermis.

'These embryos are not completely dorsalized but differentiate some derivatives of dorsolateral anlagen, like antennal sense organs.

dorsalization of the embryos (D2-D3) in trans to cact ${ }^{\wedge 2}$. The embryos of the four truncation mutations in trans to cact $^{A 2}$ show a lateralized phenotype, characterized by a loss of both ventral-most and dorsal-most structures, and an expansion of the ventral epidermis (Fig. $3 \mathrm{~d}, \mathrm{f})$. In the series of truncation mutants, the phenotypic strength of the lateralization increases if the mutant proteins get shorter. $d l^{S C}$ (stop at amino acid 598) is not completely penetrant and allows the formation of a small number of normal larvae. $d l^{(2)}$ (stop at amino acid 524) leads to a completely penetrant, but weak, lateralization. Most of the embryos derived from cact ${ }^{A 2}+1+\mathrm{dl}^{(2 l)}$ females show only a partial loss of ventral-most (mesodermal) and dorsal-most anlagen as visualized by the reduction of twi and zen expression (Fig. 4b). Finally, the shortest truncation product derived from $d l^{O 11}$ (stop at amino acid 339 ) frequently leads to a complete loss of zen expression and a strong reduction of twi expression (Fig. 4d).

The expansion of ventral epidermis at the expense of dorsal structures, which results when $d l^{Q D}$ or $d l^{O 11}$ is transheterozygous to cact, cannot be caused by the truncated proteins alone, because both proteins are weak repressors and have lost the ability to promote the differentiation of ventral epidermis. Therefore, the expansion of ventral epidermis must be the result of the wild-type copy of $d l$ protein present in these combinations. If the wild-type copy of $d l$ is removed using $\operatorname{cact}^{A 2} d l^{-} /+d l^{*}$ females (as opposed to $\mathrm{cact}^{\mathrm{A}}+1+\mathrm{dl}^{*}$ females), the mutant embryos lack all ventral epidermis (data not shown). These results suggest that the truncated proteins lead to increased nuclear concentrations of the wild-type $d l$ protein at the dorsal side when the cact amount is reduced.
However, the reduction of $t w i$ expression resulting from the same transheterozygous combinations demonstrates that the truncated proteins exert an opposite effect ventrally: They lead to an inactivation of the wild-type $d l$ protein. Therefore, at the ventral side they act in a manner similar to the dominant-negative mutation $d l^{D 7}$.

In embryos derived from cact ${ }^{A 2} d l^{-} /+d l^{*}$ females no wild-type $d l$ protein is present. Using these embryos, we could study directly the effect of the reduced cact dosage on the distribution of mutant $d l$ proteins. In the following text, we compare the truncation allele $d l^{Q D}$ to the amino-terminal group allele $d l^{5}$, which exhibits no dominant interaction with cact. As mentioned earlier, $d l^{5} /$ $\mathrm{dl}^{-}$leads to a wild-type-like nuclear protein gradient, whereas $d l^{Q D} / d l^{-}$causes an extension of the nuclear gradient toward the dorsal side (Fig. $5 \mathrm{a}, \mathrm{c}$ ). If one cact copy is removed using $+d l^{Q D} /$ cact $^{-} d l^{-}$females, this extension of the nuclear $d l$ protein gradient toward the dorsal side is even more pronounced (Fig. $5 \mathrm{c}, \mathrm{d}$ ). In contrast, we could not detect a change in the distribution of $d l^{5}$ protein in embryos derived from $+\mathrm{dl}^{5} / \mathrm{cact}^{-} \mathrm{dl}^{-}$females as compared to those derived from $d l^{5} / d^{-}$females (Fig. 5a,b). Therefore, the distribution of $d l^{Q D)}$ protein, but not the distribution of $d l^{5}$ protein, is sensitive to a reduction of the cact dosage. These observations indicate that the reduced inhibition of the nuclear transport exhibited by the $d l^{(2 l)}$ protein is accompanied by an impaired interaction with the cact product. $d l^{\text {s5 }}$ and $d l^{S(i}$ behave similarly to $d I^{(2)}$ (data not shown). In summary, the truncated proteins appear to be less susceptible to the inhibition cact exerts on the nuclear transport of the $d l$ protein. However, they clearly maintain some ability to interact with cact.

\section{Discussion}

The correlation of protein defects with the mutant phenotypes of $11 \mathrm{dl}$ alleles is informative with respect to the functional organization of the $d l$ protein. In particular, we can address the following aspects of $d l$ function: (1) DNA binding and transcriptional activation or repression; (2) control of nuclear transport and interaction with cact, and (3) self-association of the $d l$ protein.

\section{DNA binding and transcriptional activation/repression}

It has been demonstrated that the $d l$ protein binds to DNA by its RH domain. A truncated protein that contained only residues $1-378$ was as efficient as the fulllength $d l$ protein in DNA-binding assays (Ip et al. 1991). However, our data show that a truncated protein containing residues $1-488\left(\mathrm{dl}^{\mathrm{US}}\right)$ already causes a strongly dorsalized phenotype. It has lost the ability of transcriptional activation completely and possesses only a residual repression function. This suggests that the $d l$ protein is composed of at least two domains, both required for its function as a transcription factor. The $\mathrm{RH}$ domain is involved in DNA binding, and the carboxy-terminal part is required for transcriptional activation and repression. Richardson and Gilmore (1991) have shown that residues 
Figure 4. twi and zen expression of $d l$ mutants transheterozygous for a strong cact mutation. Embryos at blastoderm stage were stained simultaneously with anti-twi and anti-zen antibodies. $(a, b)$ Transverse section. Dorsal is up; ventral is down. $(c, d)$ Optical sagittal section. Anterior is to the left; ventral is down. Maternal genotypes: $(a, c) D f(2 L) T W 119 /$ Df(2L)E1ORN2. $(b)+d l^{(\alpha l)} / \mathrm{cact}^{A 2}+.|d|$ $+d l^{111} /$ cact $^{A 2}+$. Df $(2 L) T W 119$ is a dl deficiency; $D f(2 L) E 10 R N 2$ is a cact deficiency. The zen and twi expression patterns in embryos $a$ and $c$ resemble closely that of wild-type embryos. The terminal zen expression, which is unchanged in the embryo shown in $d$, is not controlled by $d l$ (Rushlow et al. 1987).

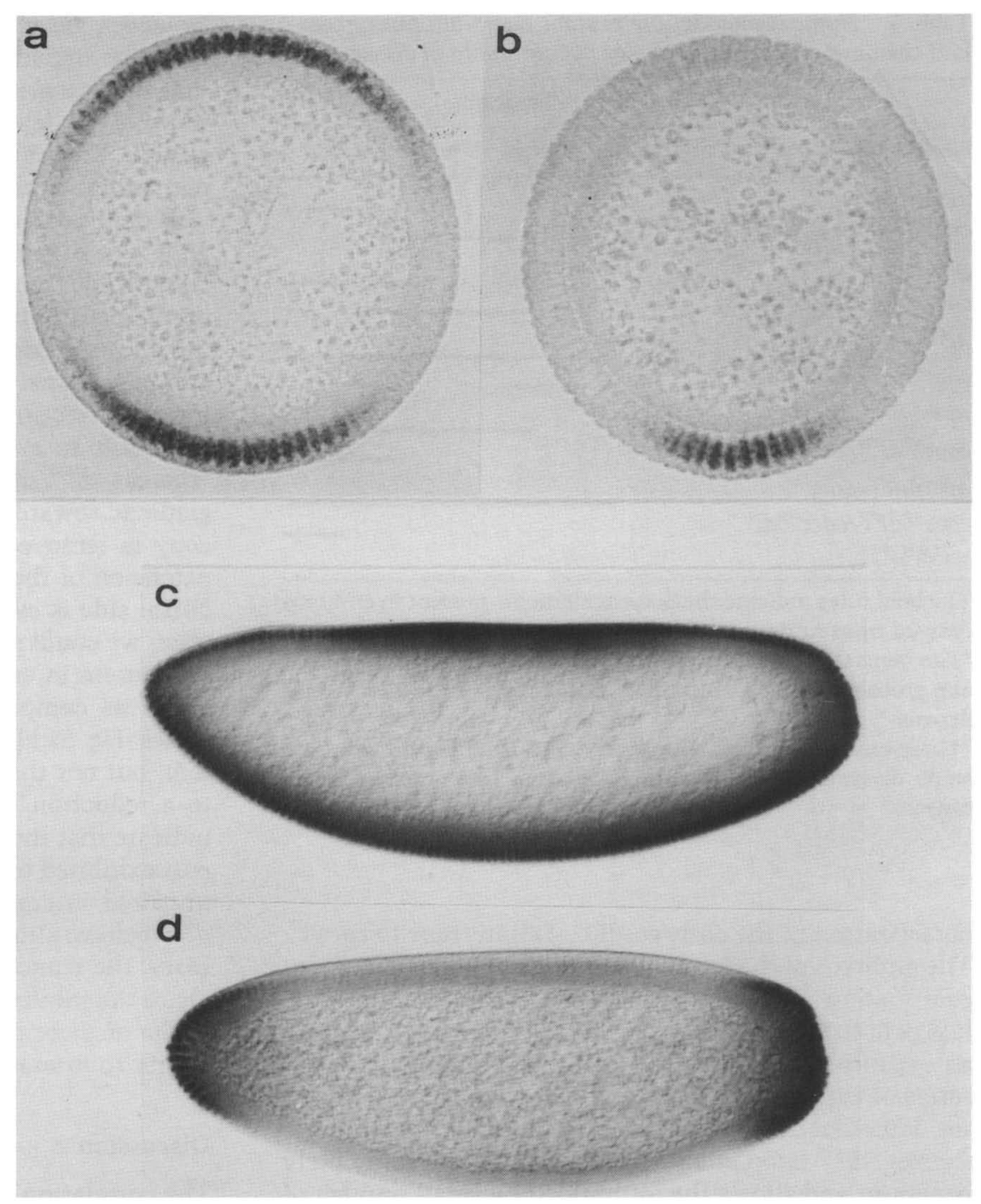

431-678 of the dl protein, bound to target DNA through the heterologous DNA-binding domain of LexA, can activate gene expression in chicken embryo fibroblasts. In these experiments the carboxy-terminal $d l$ sequences behaved similarly to the carboxy-terminal domains of chicken, mouse, and human c-Rel, even though they are not homologous or only weakly homologous to each other.

The series of truncated $d l$ proteins that we have studied show that transcriptional activation of $t w i$ and sna requires a longer carboxy-terminal region than transcriptional repression of dorsally required zygotic genes. The $d l^{S G}$ protein that is missing only 80 carboxy-terminal residues (25\% of the carboxy-terminal half) is already unable to activate twi or sna expression while its repression of dorsally required zygotic genes is similar to wild type (as inferred from the cuticle phenotype). If $>40 \%$ of the carboxy-terminal region is deleted, the truncated proteins show a reduced repressor function in addition to the lack of activation. However, even if the carboxy-ter- minal half is deleted completely and the protein consists only of the $\mathrm{RH}$ domain $\left(d l^{O 11}\right)$, the repressing function is not abolished totally.

In addition to truncated proteins, we found only one missense mutation, $d l^{3}$, that affects the activation/repression function. $d l^{3}$ may break a putative $\alpha$-helix formed by an alanine-rich region of the carboxy-terminal half. It causes an almost complete dorsalization, indicating that some higher-order structure in addition to glutamine and proline richness might be required for the function of the activation/repression domain of $d l$.

Ip et al. (1991) have further restricted the DNA-binding domain of $d l$ protein to residues 47-244, using internally deleted proteins in DNA-binding assays. Thus, only the amino-terminal part of the $\mathrm{RH}$ domain is required for DNA binding. Our calculation of the local amino acid composition shows that a region between residues 40 and 120 is more basic than the rest of the protein (with the exception of the NLS). Four of the six amino-terminal group alleles map inside or close to that 


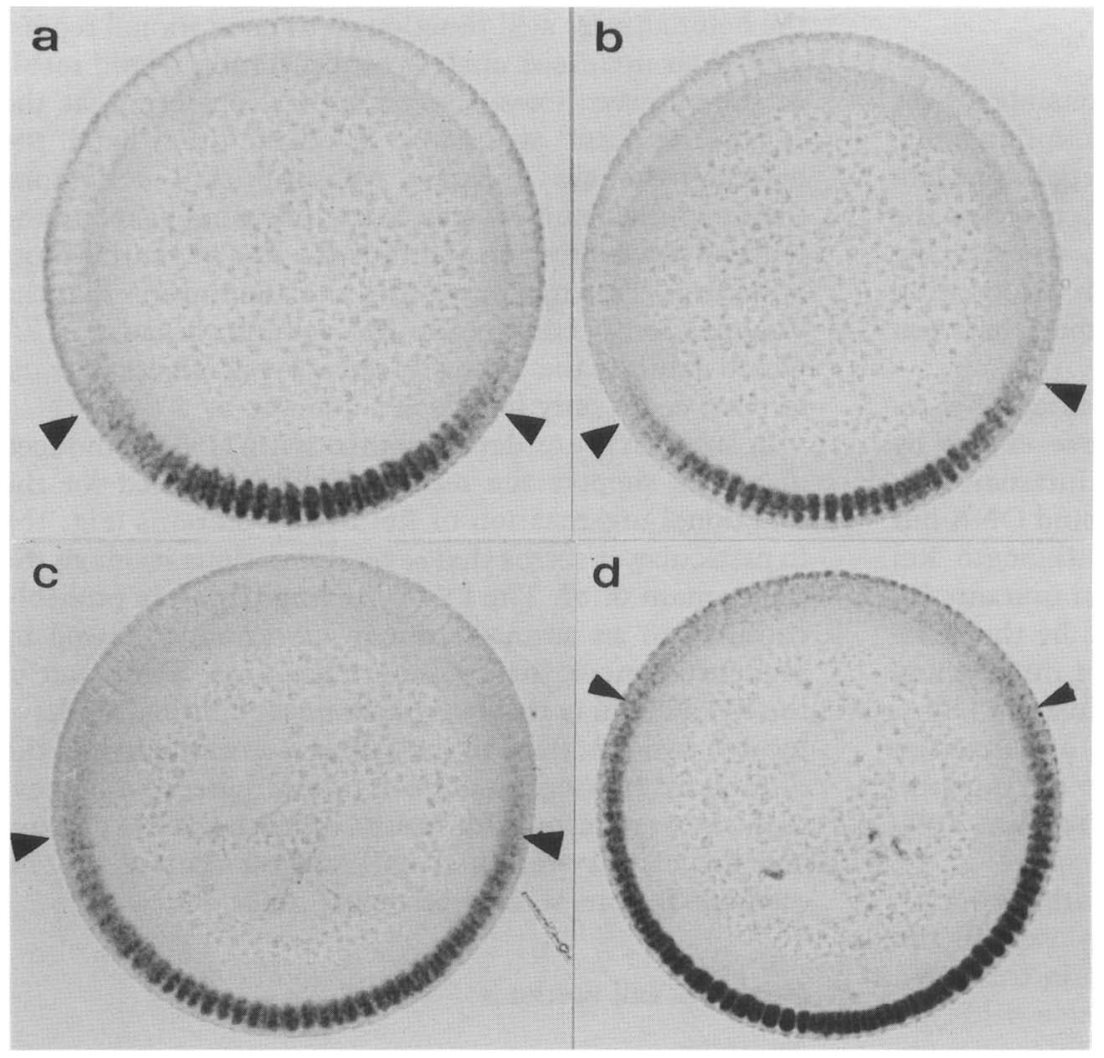

Figure 5. The $d l$ protein distribution of $d l$ mutants transheterozygous for a strong cact mutation. Embryos at blastoderm stage were stained with anti- $d l$ antibody and sectioned. Dorsal is up; ventral is down. Maternal genotypes: $(a) d l^{5}$, Df(2L)TW119. (b) $+d l^{5} /$ cact $^{A 2} d 1^{1}$. (c) $d l^{Q D} / D f(2 L) T W 119$. (d) $+d l^{Q D} /$ cact $^{A 2} d l^{1}$. $D f(2 L) T W 119$ is a $d l$ deficiency, and $d l^{1}$ is an amorphic allele. The arrowheads indicate the region of the $d l$ gradient where the concentration of the nuclear $d l$ protein becomes higher than that of the cytoplasmic dl protein. Embryos derived from $\mathrm{dl}^{5}$ / Df(2L)TW119 females $(a)$ have a wild-typelike $d l$ protein distribution, which is unchanged if cact activity is reduced $(b)$. $d l^{Q D} / d l$ causes a shift of the nuclear $d l$ protein gradient toward the dorsal side $(c)$, which is significantly enhanced if the cact activity is reduced $(d)$. basic subregion. One of those mutations, $\mathrm{dl}^{177}$, is completely nonfunctional (in trans to a deficiency). It changes the Arg-63 to Cys. The strong defect caused by this amino acid substitution is probably the result of the loss of a positive charge.

\section{Control of nuclear transport and interaction with cact}

Some of our data suggest the formation of protein complexes between cact and $d l$ proteins. Two of the aminoterminal group mutations form unstable proteins $\left(d l^{Q F}\right.$, $d l^{P Z}$, which are apparently stabilized by the presence of cact. This positive effect on $d l$ protein stability exerted by cact strongly suggests a direct and stable interaction between cact and $d l$ proteins.

If we assume complex formation with cact, it should be possible to define those parts of the $d l$ protein that are required to interact with cact. Our results indicate that sequences in both the amino- and the carboxy-terminal half are involved in the cact-mediated inhibition of nuclear transport. All of the truncated proteins are less well retained in the cytoplasm than is the wild-type $d l$ protein. They lead to nuclear $d l$ protein gradients similar to those caused by weak cact mutations (Roth 1990). However, the nuclear uptake of the truncated proteins is enhanced additionally if the cact amount is reduced. Thus, these proteins are less susceptible to the cact inhibition but still interact with cact. Because of the observed ge- netic interaction, we assume that this applies even to the smallest truncated protein $\left(d l^{O 11}\right)$, although this protein was not detectable using our antibody preparation. $d l^{011}$ consists only of the RH domain. Therefore, the RH domain alone appears to interact with cact.

I $\mathrm{B}$ interacts with $\mathrm{NF}-\kappa \mathrm{B}$ by the $\mathrm{p} 65$ subunit. Similar to our results with $d l$ and cact, progressive carboxy-terminal deletions of $\mathrm{p} 65$ demonstrate that $\mathrm{I} \mathrm{KB}$ binds to the $\mathrm{RH}$ domain of p65 (Nolan et al. 1991). If we assume that cact interacts primarily with the RH domain of $d l$ protein, the question arises why carboxy-terminal sequences are involved in the inhibition of nuclear transport. Two explanations are possible. The presence of the carboxy-terminal region may stabilize the $d l$-cact interaction or may represent a second site of cact binding. Alternatively, the carboxy-terminal region could interact with a cytoplasmic anchoring protein (not yet identified), whereas cact would be required to strengthen this interaction.

The implication of carboxy-terminal sequences for the cytoplasmic retention of the $d l$ protein had been proposed earlier on the basis of tissue culture experiments (Rushlow et al. 1989). It might be a general feature of Rel family proteins, because it was also observed for avian c-Rel. Chicken c-Rel is cytoplasmic in chicken embryo fibroblasts. If 103 carboxy-terminal residues are removed, the truncation protein enters the nucleus /Capobianco et al. 1990). 


\section{Self-association of the $\mathrm{dl}$ protein}

One of the mechanisms known to be responsible for the dominant-negative action of mutant transcriptional regulators (for review, see Herskowitz 1987) applies to proteins that are able to self-associate. In such proteins the DNA-binding domain can be inactivated, whereas the oligomerization domain is not affected. An inactivation of wild-type protein results when multimers between mutant and wild-type proteins are formed.

Logeat et al. (1991) have shown that mutant Rel-related proteins can cause dominant-negative effects by this mechanism. They have constructed internal deletion mutants of p50, which are unable to bind DNA but can form homo- or heterodimers with full-length Rel family proteins (p50, c-Rel). These deletion mutants inhibit the transcriptional activation caused by the wildtype proteins, because the heterodimers of mutant and wild-type protein are apparently unable to bind DNA. The deletion mapping of $\mathrm{p} 50$ restricts the dimerization region to the carboxy-terminal part of the $\mathrm{RH}$ domain. This region corresponds approximately to residues 180 350 of the $d l$ protein.

A dimerization of the $d l$ protein by the carboxy-terminal part of the $\mathrm{RH}$ domain would readily explain the phenotype of $d l^{D 7}$, which is nonfunctional in trans to a deficiency but dominant negative in trans to a wild-type copy of $d l . d l^{D 7}$ is probably unable to bind DNA owing to a single amino acid change in the proposed DNA-binding domain. However, it should still form heterodimers with the wild-type $d l$ protein because the potential dimerization domain is unaltered. These heterodimers might be nonfunctional or only partially functional. Thus, the heterodimerization would cause an inactivation of the wild-type protein.

There is one other strongly dorsalizing allele, $d l^{5}$, which, like $d l^{L 7}$, produces normal amounts of fulllength protein and leads to the formation of a normal nuclear gradient. Unlike $d l^{D 7}, d l^{5}$ is not dominant. Interestingly, $d l^{5}$ does not map to the putative DNA-binding domain but to the region corresponding to the dimerization domain in p50. A mutation that disrupts dimerization should be unable to inactivate the wild-type copy.

The dominant effect exhibited by the truncated proteins when the cact amount is reduced may also be attributed to the dimerization of the $d l$ protein. In trans. heterozygous combinations with cact, the truncated proteins lead to a lateralized phenotype simultaneously deleting both dorsal-most and ventral-most structures. To explain this phenotype we postulated that the truncated proteins increase the wild-type activity of $d l$ at the dorsal side but inactivate wild-type $d l$ ventrally. This complicated effect might be the result of the formation of heterodimers between truncated and full-length proteins. Because the nuclear import of truncated proteins is less inhibited by cact, we assume that this applies also to heterodimers of truncated and full-length proteins. Therefore, increased nuclear concentrations of the heterodimer would result when cact activity is reduced. If the heterodimers still function as transcriptional repressors, their increased nuclear concentration would result in the observed expansion of ventral epidermis at the expense of dorsal structures. If, on the other hand, the heterodimers are impaired transcriptional activators, their increased nuclear concentrations would explain the reduced twi expression and thus the loss of ventral-most structures. This model requires the assumption that the dimerization occurs by the RH domain, because $d l^{011}$, which exhibits the strongest phenotypic effects in trans to cact, codes only for the RH domain.

In summary, our data obtained with 11 EMS-induced dl alleles support the recent models proposed for the functional organization of Rel family proteins (Fig. 1b). In particular, it seems that several functions reside in the $\mathrm{RH}$ domain of $d l$. The DNA-binding region is probably confined to an amino-terminal subregion, followed by sequences important for dimer formation. Some part of the $\mathrm{RH}$ domain is also required for cact binding. We have located two functions to the carboxy-terminal half of the dl protein: transcriptional activation/repression and cytoplasmic retention. Our results on both the $\mathrm{RH}$ domain and the carboxy-terminal half suggest that $d l$ protein contains regions with overlapping functions.

\section{Materials and methods}

Fly strains

The wild-type stock was Oregon-R. All of the $d l$ alleles are described in Roth et al. (1989), and the cact alleles are described in Roth et al. (1991). Flies were grown and eggs were collected under the standard conditions (Nüsslein-Volhard et al. 1984). Staging of embryos was according to Campos-Ortega and Hartenstein (1985).

\section{DNA sequencing}

Genomic DNA was extracted from the flies transheterozygous for $d l$ alleles and the deficiency $D f(2 L) T W 119$. We amplified the DNA of the coding region of each $d l$ mutant gene in four pieces of DNA by polymerase chain reaction (PCR). The first piece includes 1-988 bp, the second includes $989-1096 \mathrm{bp}$, the third includes $1097-1545 \mathrm{bp}$, and the last includes $1309-2037 \mathrm{bp}$. The PCR products were subcloned into $\mathrm{M} 13 \mathrm{mpl} 0$ and sequenced by the dideoxy chain-termination method. All of the mutant genes were sequenced over the whole coding region. When we found a nucleotide change that caused a change of amino acid residue, two to three different clones of the PCR products were sequenced to confirm it. All of the reactions were made according to Sambrook et al. (1989).

Some deletions and insertions were observed in more than one mutant or in some clones of a certain mutant and not others. We show them in terms of amino acid residues in the following: the deletion of QQ between residue 479 and 482 (in $d l^{5}$, $d l^{011}, d l^{U 5}$, and $d l^{3}$ ); Q between residue 495 and 503 (in some $d l^{Q D}$ and not in some $d l^{Q D}$ ); $\mathrm{Q}$ between residue 600 and 606 (in $d l^{5}, d l^{011}, d l^{U 5}$, and $d l^{3}$; $\mathrm{N}$ between residue 614 and 615 (in $d l^{D^{7}}, d l^{Q F}, d l^{S G}, d l^{P Z}, d l^{011}, d l^{U 5} d l^{Q D}, d l^{3}$, and $d l^{S G}$; ; and the insertions of QQQ and Q between residue 495 and 503 (both in $d l^{3}$ ), one of the same as the previous one, that is, QQQ between residue 495 and 503 (in $d l^{5}$ ). NPNNG between residue 615 and 616 (in $d l^{5}, d l^{011}$, and $\left.d l^{U 5}\right)$. All of them are located in glutamine (Q)- and asparagine (N)-rich regions in the carboxy-terminal half 
of the $d l$ protein. Because they are very common to many alleles with different phenotypes or they are observed only in a part of the clones from the same mutants, we interpret them to be polymorphism independent of the mutant phenotypes.

\section{Cuticle preparations of embryos}

Differentiated embryos were dissected from the vitelline membrane and mounted directiy in a $1: 1$ mixture of lactic acid and Hoyer's medium (Van der Meer 1977).

\section{Antibody staining of embryos}

Immunological staining of whole-mount embryos, using the $\mathrm{ABC}$ system (Vector Laboratory), was carried out as described by Roth et al. (1989). The sections shown in the figures are derived from $40 \%$ to $50 \%$ egg length.

\section{Acknowledgments}

We thank the following colleagues for their contributions to this work: R. Brock for excellent technical assistance; C. Rushlow for providing the zen antibody used in this study; $\mathrm{T}$. Schüpbach and J. Szabad for the gift of $d l$ alleles; and D. St. Johnston, D. Stein, T. Schüpbach, S. Govind, and C. Rushlow for discussions and critical reading of the manuscript.

The publication costs of this article were defrayed in part by payment of page charges. This article must therefore be hereby marked "advertisement" in accordance with 18 USC section 1734 solely to indicate this fact.

\section{References}

Anderson, K.V. and C. Nüsslein-Volhard. 1986. Dorsal-group genes of Drosophila. In Gametogenesis and the early embryo (ed. J. Gall), pp. 177-194. Alan R. Liss, New York.

Anderson, K.V., G. Jürgens, and C. Nüsslein-Volhard. 1985. Establishment of dorsal-ventral polarity in the Drosophila embryo: Genetic studies on the role of the Toll gene product. Cell 42: 779-789.

Baeuerle, P.A. 1991. The inducible transcription activator NF$\kappa \mathrm{B}$ : Regulation by distinct protein subunits. Biochem. Biophys. Acta 1072: 63-80.

Baeuerle, P.A. and D. Baltimore. 1988. Activation of DNA-binding activity in an apparently cytoplasmic precursor of the NF-kB transcription factor. Cell 53: 211-217.

Bull, P., K.L. Morley, M.L. Hoekstra, T. Hunter, and I.M. Verma. 1990. The mouse c-rel protein has an $\mathrm{N}$-terminal regulatory domain and a C-terminal transcriptional transactivation domain. Mol. Cell. Biol. 10: 5473-5485.

Campos-Ortega, J.A. and V. Hartenstein. 1985. The embryonic development of Drosophila melanogaster. Springer Verlag, Berlin, Germany.

Capobianco, A.J., D.L. Simmons, and T.D. Gilmore. 1990. Cloning and expression of a chicken c-rel cDNA: Unlike p $59^{\mathrm{v}-\mathrm{rel}}$, p $68^{\mathrm{c}-r e l}$ is a cytoplasmic protein in chicken embryo fibroblasts. Oncogene 5: 257-265.

Davis, N., S. Ghosh, D.L. Simmons, P. Tempst, H.-C. Liou, D. Baltimore, and H.R. Bose Jr. 1991. Rel-associated pp40: An inhibitor of the rel family of transcription factors. Science 253: 1268-1271.

Garnier, J., D.J. Osguthorpe, and B. Robson. 1978. Analysis of the accuracy and implications of simple methods for predicting the secondary structure of globular proteins. J. Mol. Biol. 120: $97-120$.

Ghosh, S. and D. Baltimore. 1990. Activation in vitro of NF- $\mathrm{kB}$ by phosphorylation of its inhibitor IKB. Nature 344: 678682 .
Ghosh, S., A.M. Gifford, L.R. Riviere, P. Tempst, G.P. Nolan, and D. Baltimore. 1990. Cloning of the p50 DNA binding subunit of NF-kB: Homology to rel and dorsal. Cell 62: 1019-1029.

Gilmore, T.D. 1991. Malignant transformation by mutant Rel proteins. Trends Genet. 7: 318-322.

Goldenberg, D.P. 1988. Genetic studies of protein stability and mechanisms of folding. Annu. Rev. Biophys. Chem. 17: 481-507.

Harrison, S.C. 1991. A structural taxonomy of DNA-binding domains. Nature 353: 715-719.

Hashimoto, C., K.L. Hudson, and K.V. Anderson. 1988. The Toll gene of Drosophila, required for dorsal-ventral embryonic polarity, appears to encode a transmembrane protein. Cell 52: $269-279$.

Haskill, S., A.A. Beg, S.M. Tompkins, J.S. Morris, A.D. Yurochko, A. Sampson-Johannes, K. Mondal, P. Ralph, and A.S. Baldwin Jr. 1991. Characterization of an immediate-early gene induced in adherent monocytes that encodes I- $\mathrm{kB}$-like activity. Cell 65: 1281-1289.

Herskowitz, I. 1987. Functional inactivation of genes by dominant negative mutations. Nature 329: 219-222.

Inoue, J.-I., L.D. Kerr, L.J. Ransone, E. Bengal, T. Hunter, and I.M. Verma. 1991. c-rel activates but v-rel suppresses transcription from $\kappa \mathrm{B}$ sites. Proc. Natl. Acad. Sci. 88: 37153719.

Ip, Y. T., R. Kraut, M. Levine, and C.A. Rushlow. 1991. The dorsal morphogen is a sequence-specific DNA-binding protein that interacts with a long-range repression element in Drosophila. Cell 64: 439-446.

Irish, V. F. and W.M. Gelbart. 1987. The decapentaplegic gene is required for dorsal-ventral patterning of the Drosophila cmbryo. Genes \& Dev. 1: 868-879.

Jiang, J., D. Kosman, Y.T. Ip, and M. Levine. 1991. The dorsal morphogen gradient regulates the mesoderm determinant twist in early Drosophila embryos. Genes \& Dev. 5: 18811891.

Kerr, L.D., J.-I. Inoue, N. Davis, E. Link, P.A. Baeuerle, H.R. Bose Jr., and M. Verma. 1991. The Rel-associated pp40 protein prevents DNA binding of Rel and NF-kB: Relationship with I $\mathrm{B} \beta$ and regulation by phosphorylation. Genes \& Dev. 5: $1464-1476$.

Kieran, M., V. Blank, F. Logeat, J. Vandekerckhove, F. Lottspeich, O. Le Bail, M.B. Urban, P. Kourilsky, P.A. Baeuerle, and A. Israël. 1990. The DNA binding subunit of NF- $\mathrm{B}$ is identical to factor $\mathrm{KBF} 1$ and homologous to the rel oncogene product. Cell 62: 1007-1018.

Letsou, A., S. Alexander, K. Orth, and S.A. Wasserman. 1991. Genetic and molecular characterization of tube, a Droso. phila gene maternally required for embryonic dorsoventral polarity. Proc. Natl. Acad. Sci. 88: 810-814.

Logeat, F., N. Israël, R. Ten, V. Blank, O. Le Bail, P. Kourilsky, and A. Israel. 1991. Inhibition of transcription factors belonging to the rel/NF- $\mathrm{kB}$ family by a transdominant negative mutant. $E M B O$ I. 10: 1827-1832.

Mitchell, P. and R. Tiian. 1989. Transcriptional regulation in mammalian cells by sequence-specific DNA binding proteins. Science 245: 371-378.

Nolan, G. P., S. Ghosh, H. Liou, P. Tempst, and D. Baltimore. 1991. DNA binding and IкB inhibition of the cloned p65 subunit of NFkB, a rel-related polypeptide. Cell 64: 961-969.

Nüsslein-Volhard, C. 1979. Maternal effect mutations that alter the spatial coordinates of the embryo of Drosophila melanogaster. In Determinants of spatial organization (ed. S. Subtelny and I.R. Koenigsberg), pp. 185-211. Academic Press, New York. 
Nüsslein-Volhard, C., E. Wieschaus, and H. Kluding. 1984. Mutations affecting the pattern of the larval cuticle in Drosophila melanogaster. I. Zygotic loci on the second chromosome. Wilhelm Roux's Arch. Dev. Biol. 183: 267-282.

Pan, D., J.-D. Huang, and A.J. Courey. 1991. Functional analysis of the Drosophila twist promoter reveals a dorsal-binding ventral activator region. Genes \& Dev. 5: 1892-1901.

Ray, R.P., K. Arora, C. Nüsslein-Volhard, and W. Gelbart. 1991. The control of cell fate along the dorsal-ventral axis of the Drosophila embryo. Development 113: 35-54.

Richardson, P. and T.D. Gilmore. 1991. vRel is an inactive member of the rel family of transcriptional activating proteins. J. Virol. 65: 3122-3130.

Roth, S. 1990. "Die Rolle der maternalen Gene cactus und dorsal bei der dorsoventralen Musterbildung im Drosophila Embryo." Ph.D. thesis, University of Tübingen, Tübingen, Germany.

Roth, S., D. Stein, and C. Nüsslein-Volhard. 1989. A gradient of nuclear localization of the dorsal protein determines dorsoventral pattern in the Drosophila embryo. Cell 59: 11891202.

Roth, S., Y. Hiromi, D. Godt, and C. Nüsslein-Volhard. 1991. cactus, a maternal gene required for proper formation of the dorsoventral morphogen gradient in Drosophila embryos. Development 112: 371-388.

Ruben, S.M., P.J. Dillon, R. Schreck, T. Henkel, C.-H. Chen, M. Maher, P.A. Bacuerle, and C.A. Rose. 1991. Isolation of a rel-related human cDNA that potentially encodes the $65-\mathrm{kD}$ subunit of NF-kB. Science 251: 1490-1493.

Rushlow, C., M. Frasch, H. Doyle, and M. Levine. 1987. Maternal regulation of zerknüllt: A homeobox gene controlling differentiation of dorsal tissues in Drosophila. Nature 330: $583-586$.

Rushlow, C.A., K. Han, J.L. Manley, and M. Levine. 1989. The graded distribution of the dorsal morphogen is initiated by selective nuclear transport in Drosophila. Cell 59: 11651177.

Sambrook, J., E.F. Fritsch, and T. Maniatis. 1989. Molecular cloning: A laboratory manual, 2nd ed. Cold Spring Harbor Laboratory Press, Cold Spring Harbor, New York.

Stein, D., S. Roth, E. Vogelsang, and C. Nüsslein-Volhard. 1991. The polarity of the dorsoventral axis in the Drosophila em. bryo is defined by an extracellular signal. Cell 65: 725-735.

Stephens, R.M., N.R. Rice, R.R. Hiebsch, H.R. Bose Jr., and R.V. Gilden. 1983. Nucleotide sequence of v-rel: The oncogene of reticuloendotheliosis virus. Proc. Natl. Acad. Sci. 80: 62296233.

Steward, R. 1987. Dorsal, an embryonic polarity gene in Drosophila, is homologous to the vertebrate protooncogene, c-rel. Science 238: 692-694.

1989. Relocalization of the dorsal protein from the cytoplasm to the nucleus correlates with its function. Cell 59: 1179-1188.

Thisse, C., F. Perrin-Schmitt, C. Stoetzel, and B. Thisse. 1991. Sequence-specific transactivation of the Drosophila twist gene by the dorsal gene product. Cell 65: 1-20.

Urban, M.B., R. Schreck, and P.A. Baeuerle. 1991. NF-кB contacts DNA by a heterodimer of the p50 and p 65 subunit. EMBO \%. 10: 1817-1825.

Van der Meer, J.M. 1977. Optical clean and permanent whole mount preparations for phase-contrast microscopy of cuticular structures of insect larvae. Dros. Inf. Serv. 52: 160.

Wilhelmsen, K., K. Eggleton, and H. Temin. 1984. Nucleic acid sequence of the oncogene $\mathrm{v}$-rel in reticuloendotheliosis virus strain $\mathrm{T}$ and its cellular homolog, the proto-oncogene c-rel.J. Virol. 52: 172-182. 


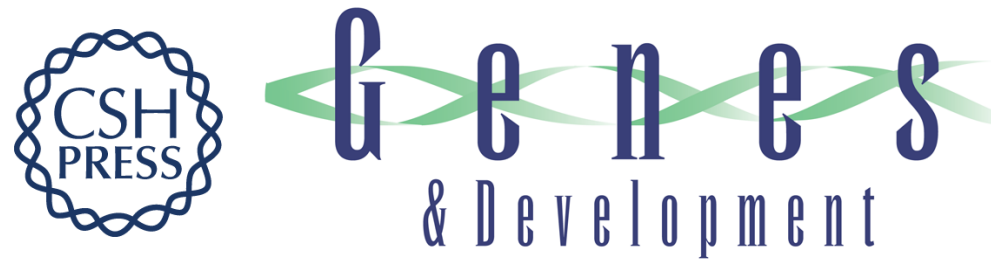

\section{The functional domains of the Drosophila morphogen dorsal: evidence from the analysis of mutants.}

K Isoda, S Roth and C Nüsslein-Volhard

Genes Dev. 1992, 6:

Access the most recent version at doi:10.1101/gad.6.4.619

References This article cites 42 articles, 16 of which can be accessed free at:

http://genesdev.cshlp.org/content/6/4/619.full.html\#ref-list-1

License

Email Alerting

Service

Receive free email alerts when new articles cite this article - sign up in the box at the top right corner of the article or click here.

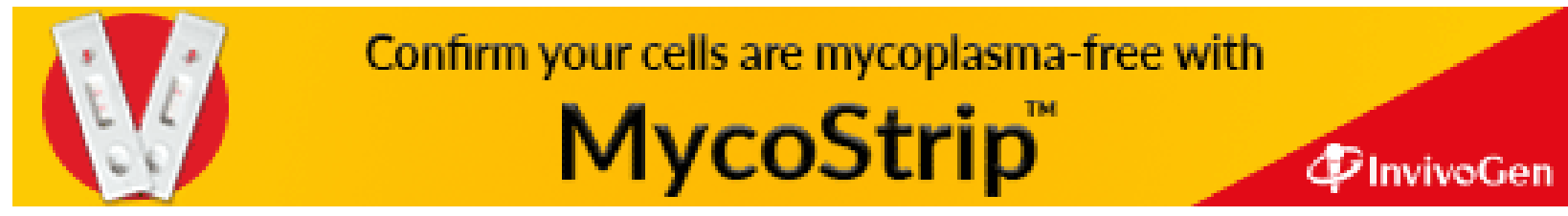

